\title{
Non-digestible oligosaccharides and defense functions: lessons learned from animal models
}

\author{
R. K. Buddington ${ }^{1,2} *$, K. Kelly-Quagliana ${ }^{3}$, K. K. Buddington ${ }^{1}$ and Y. Kimura ${ }^{4}$ \\ ${ }^{1}$ Department of Biological Sciences, Mississippi State University, Mississippi State, MS 39762-5759, USA \\ ${ }^{2}$ College of Veterinary Medicine, Mississippi State, MS 39762, USA \\ ${ }^{3}$ Department of Animal and Dairy Sciences, Mississippi State, MS 39762, USA \\ ${ }^{4}$ Otsu Nutraceuticals Research Institute, Otsuka Pharmaceutical Co., Ltd., 31-13 3-Chome Saigawa Otsu, Shiga 520-0002 \\ Japan
}

\begin{abstract}
Animals are constantly exposed to a diversity of health challenges and the gastrointestinal tract (GIT) is a major, if not the principal, site of exposure. Animal models and a limited number of human clinical studies have shown that the assemblages and metabolic activities of the resident bacteria are important determinants of the effectiveness of the various host defense mechanisms and thereby influence the ability of animals to respond to health challenges. The assemblages of bacteria resident in the GIT provide a first line of defense that can exclude invading pathogens, reduce the proliferation of opportunistic pathogens already resident in the GIT, and reduce the availability, carcinogenicity, or toxicity of noxious chemicals. The mucosa of the GIT is a second, multilayered line of defense that includes the mucous and other secretions, the epithelial cells, and immune-associated cells scattered within and under the epithelium. The final line of defense contends with pathogens or noxious chemicals that transcend the mucosal barrier and enter the host and consists of the innate and acquired components of the systemic immune system and the xenobiotic metabolizing enzymes. The lactic acid producing bacteria (LAB) are considered to be immunomodulatory and directly or indirectly influence the GIT and systemic defense functions. Corresponding with this, supplementing the diet with inulin, oligofructose, or other nondigestible oligosaccharides that increase the densities and metabolic capacities of the LAB enhances defense mechanisms of the host, increases resistance to various health challenges, and accelerates recovery of the GIT after disturbances.
\end{abstract}

及-fructans: Inulin: Oligofructose: Oligosaccharides: Immune: Lactic acid bacteria: Gastrointestinal tract

\section{Introduction}

The internal and external environments of animals and humans provide constant and varying challenges to health and well-being. To cope with these challenges, animals have evolved a wide diversity of defense mechanisms. These include physical and functional barriers to invasions, the abilities to recognize and eliminate harmful organisms that do invade, and transformation of potentially harmful substances, while tolerating self and beneficial organisms and substances.

Host defense functions are dependent on adequate intakes of energy and nutrients (Cunningham-Rundles \& Lin, 1998), particularly after surgery, trauma, and other inducers of stress (Bengmark \& Jeppsson, 1995). Fiber is recognized as a critical component of the diet and is necessary to promote the most effective defenses (Frankel et al. 1995; Spaeth et al. 1990). Fermentable forms of fiber, such as inulin, oligofructose and other nondigestible oligosaccharides (NDO), represent a nutrient source to the resident bacteria and indirectly provide nutrition to the host as short-chain fatty acids (SCFA), vitamins, and other bacterial metabolites. Supplementing the diet with some NDO identified as prebiotics changes the proportions and metabolic characteristics of the resident bacteria (Gibson \& Roberfroid, 1995). The specific responses of the host and the magnitude of benefits vary among the amounts and sources of fiber, and involve complex interactions between the host and the bacteria resident in the gastrointestinal tract (GIT).

This review examines if and how, supplementing the diet with fiber, particularly NDO, and more specifically

\footnotetext{
Abbreviations: GIT, gastrointestinal tract; LAB, lactic acid producing bacteria; NDO, nondigestible oligosaccharides; SCFA, short-chain fatty acids. Note: For the definition of the terms inulin and oligofructose please refer to the introductory paper (p. S139) and its footnote.

* Corresponding author: Dr R. K. Buddington, tel +0 662325 7580, fax +0 662325 7939, email rkb1@ ra.msstate.edu
} 
inulin and oligofructose, influences the defense functions of animals and thereby increases resistance to pathogens, environmental contaminants, and other health challenges. The components of the defense system are considered to include the bacteria resident in the GIT, the various defense functions of the GIT that limit invasion, and the systemic defense functions that respond to organisms or compounds that do manage to escape the primary GIT defenses and enter the body. In addition to the innate and acquired components of the immune system, the xenobiotic metabolizing enzymes of the host provides animals with a defense against numerous compounds that are detrimental to normal host physiology. These compounds include the secondary metabolites of plants that have evolved to reduce herbivory and anthropogenic sources of dangerous chemicals, which are more recent health risks. The natural and man-made noxious compounds are often not recognized by the immune system, but must be eliminated or detoxified. This is accomplished by the Phase I and II xenobiotic metabolizing enzymes that are expressed in the GIT and other tissues.

The complex interactions between the GIT bacteria and the various defense functions of the host diet are modulated by diet composition, including the amounts and types of fiber. The interactions are difficult to explore and understand in humans, especially when genetic and phenotypic variation are considered (Szilagyi, 1997). Animal models have been, and continue to be, instrumental in providing much needed information and insights. There is general agreement that NDO enhance resistance to some health challenges, but only a very few studies have directly examined if and how NDO enhance defense mechanisms. The objective of this review is to provide readers with an understanding of topics relevant to how diets supplemented with NDO might enhance defense functions, with the emphasis on inulin and oligofructose. We first provide examples demonstrating that NDO increase resistance to a variety of health challenges. Subsequent sections describe how the increased resistance to health challenges conferred by NDO may involve different components of the integrated defense systems of animals. Because of the limited

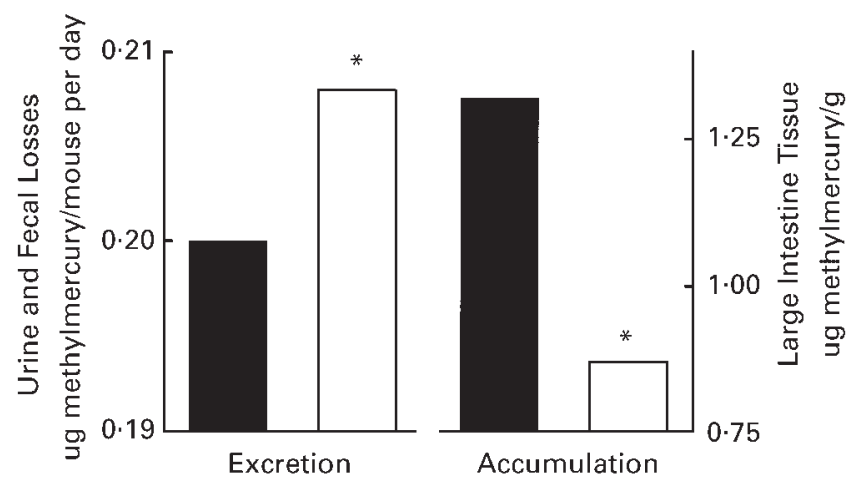

Fig. 1. Methylmercury excreted in the urine and feces and accumulated in the large intestinal tissue of mice fed diets with $100 \mathrm{~g} / \mathrm{kg}$ fiber as cellulose ( $\square$ ) or inulin ( $\square$ ) and exposed to methylmercury daily for 2 weeks (from Kimura et al. 2002). The asterisks indicate mice fed the diet with inulin excreted more and accumulated less methylmercury than those fed the diet with cellulose $(P<0.05)$. number of studies that have directly examined the interactions among dietary fiber, defense mechanisms, and resistance to health challenges, readers are cautioned that some of the findings and interpretations must be considered as speculative. The papers selected for this review will provide interested readers with a 'starting point' toward understanding if and how inulin, oligofructose and other NDO enhance defense functions.

\section{Resistance to health challenges conferred by inulin, oligofructose and other nondigestible oligosaccharides}

\section{Resistance to lumenal pathogens}

The mature GIT ecosystem is resistant to colonization by invading species or to overgrowth by opportunistic pathogens that are already present (Bengmark, 1998). The protection provided by the resident bacteria is highlighted by the much lower infective dose of pathogens required to kill gnotobiotic mice compared to those with a GIT harboring even simple assemblages of bacteria (Zachar \& Savage, 1979). Additional protection can be obtained by encouraging higher densities of lactic acid producing bacteria (LAB), either by supplementing the diet with NDO or probiotics. Corresponding with this, supplementing the diets of chickens, pigs, and rats with oligofructose and other NDO reduces fecal densities of Salmonella (Letellier et al. 2000; Fukata et al. 1999; Bovee-Oudenhoven et al. 1997; Bailey et al. 1991). Similarly, supplementing the diet of mice with inulin and oligofructose reduces densities of Candida in the small intestine of mice $7 \mathrm{~d}$ after infection (Buddington et al. 2002), increases colonization resistance to Clostridium difficile after antibiotic treatment (Gaskins et al. 1996; May et al. 1995), and protects gnotobiotic quail inoculated with bacteria associated with necrotizing enterocolitis (Catala et al. 1999).

The benefits of protective diet components, such as NDO, are more profound for young animals that have an immature GIT, an undeveloped immune system, and unstable bacterial assemblages (Dai \& Walker, 1999). Breast milk confers greater resistance to pathogens than to commercially available formulas and this is partly attributed to the higher densities and proportions of LAB in the GIT of breast-fed infants. These findings have led to a search for compounds that increase the abundance of LAB in the GIT of infants dependent on foods other than breast milk. Although NDO are added to some infant formulas, studies are lacking about the influence on colonization resistance and defense functions.

A major, and frontline, mechanism of host defense is the mucosal barrier. Dietary inputs are the principal source of energy and nutrients for the GIT, and as a result patients and animals dependent on parenteral nutrition have a reduced mucosal barrier. As a consequence they suffer a higher incidence of bacterial translocation. Combining fiber with enteral nutrients enhances the barrier functions (Frankel et al. 1995; Deitch et al. 1993; Spaeth et al. 1990) and can accelerate recovery from the detrimental influences of 5-fluorouracil (Deng et al. 1999) and $\gamma$-radiation (Ishizuka et al. 2000). Although the majority of studies have used cellulose or other fibers that are poor nutrient 
sources for the resident bacteria, the limited information available indicates inulin, oligofructose, and other NDO further enhance the mucosal barrier (Chinery et al. 1992). The ability of probiotic lactobacilli to reduce the extent of GIT damage caused by the chemotherapeutic agent methotrexate (Mao et al. 1996) suggests the beneficial responses to NDO involve the associated changes in bacterial assemblages.

\section{Resistance to noxious chemicals in the diet}

Dietary inputs can expose animals to noxious substances. Of particular interest are environmental contaminants, drugs, pesticides, and other potentially detrimental compounds of anthropogenic origin. Supplementing a mouse diet with inulin increases fecal losses and thereby reduces accumulation of methylmercury compared to a diet with cellulose or lacking fiber (Fig. 1). Interestingly, the diet with inulin did not diminish the absorption, increase fecal losses, or reduce accumulation of retinol (Kimura et al. 2002). Adding wheat bran to the diet of mice also reduces mercury retention (Rowland et al. 1986), and the viscous indigestible polysaccharides sodium alginate and guar gum reduce the accumulation of pentachlorobenzene by rats (Ikegami et al. 1994). Using rice bran, corn, soybean, spinach, and burdock as sources of fiber in rat diets increases excretion and reduces accumulation of polychlorinated dibenzofurans, polychlorinated dibenzo- $p$ dioxins, and polychlorinated biphenyls (Morita et al. 1995, 1993).

Inulin, oligofructose, and other NDO increase resistance to carcinogens and reduce the growth of spontaneous and transplantable tumors (Pool-Zobel et al. 1996; present volume). However, the inability of $\beta$-fructans to reduce the incidence of lung tumors in mice after challenge with B16F10 tumor cells (Buddington et al. 2002) indicates that protection is not provided against all such challenges.

\section{Surviving systemic challenges with pathogens}

Translocation of GIT pathogens into the interior or systemic circulation of the host is a cause of morbidity and mortality and often results when the mucosal barrier is damaged or diminished. Mice infected systemically with virulent strains of Listeria monocytogenes and Salmonella typhimurium after being fed a diet with inulin and oligofructose (at $100 \mathrm{~g} / \mathrm{kg}$ ) had lower mortality than mice fed a diet with cellulose as the source of fiber (Buddington et al. 2002). Interestingly, inulin provided greater resistance than oligofructose to the systemic infections, significantly so for the Listeria challenge.

\section{Accelerating recovery of disturbed gastrointestinal tract ecosystems}

Diarrhea disturbs the physical, functional, and biotic characteristics of the GIT, much like floods disturb river systems. After a disturbance, the recovery of the GIT ecosystem is dependent on restoring the normal balance of bacterial species. However, undesirable species, which often are opportunistic pathogens, usually recover faster than commensal species, often leading to secondary infections. Although the majority of attention has focused on accelerating restoration of the LAB, other commensal bacterial groups need to be considered (Rembacken et al. 1999). Probiotics hasten recovery from diarrhea by reestablishing the populations of LAB and decreasing the densities of potential pathogens (Guandalini et al. 2000; Vanderhoof et al. 1999). Probiotics consisting of LAB extend similar benefits to patients suffering from Crohn's disease (Malin et al. 1996) and other inflammatory bowel diseases (Shanahan, 2000). Adding oligofructose to an oral rehydration solution accelerates recovery of LAB species endemic to the GIT, reduces the magnitude of increase in enterics (Oli et al. 1998), and hastens restoration of the structural and functional characteristics of the GIT (Chandra et al. 1996). Similarly, the enteropathy induced by indomethacin is less severe when rats are provided with the NDO lactosucrose (Honda et al. 1999). There is also evidence that supplementing the diet with NDO helps dogs and cats recover from large intestinal diseases (Simpson, 1998).

\section{Defense mechanisms and responses to inulin, oligofructose, other nondigestible oligosaccharides and other sources of dietary fiber}

Inulin, oligofructose and other NDO are not considered to be immunogenic and apparently do not directly induce the expression of various enzyme systems associated with xenobiotic metabolism. Instead, the majority of influences of NDO on defense functions, and thereby health, can be attributed directly or indirectly to changes in the population and metabolic characteristics of the bacterial assemblages present in the GIT (Bengmark, 1998). In addition, dietary fiber can adsorb some noxious chemicals, increase microbial mass and stool volume, and shorten residence time of digesta, and thereby decrease exposure to the host (Berdanier, 1994; Cummings et al. 1992).

The complex, multi-species assemblages of bacteria characteristic of humans and 'normal' animals are hard to study and this has complicated attempts to examine if and how diets supplemented with NDO influence defense functions. Probiotics and the use of gnotobiotic and genetically modified animals have provided valuable insights into the interactions between the GIT bacteria and defense functions of the host (Fuller \& Perdigon, 2000; Umesaki \& Setoyama, 2000; Erickson \& Hubbard, 2000; Falk et al. 1998). Perhaps the most dramatic example is the lack of resistance gnotobiotic animals have to lumenal pathogens (Zachar \& Savage, 1979). Simply establishing a limited number of species from the 'normal' commensal flora provides protection against invasions by pathogens. The importance of the GIT bacteria led to the development of the Altered Schaedler Flora, which is used to improve the health and disease resistance of rodent models (Dewhirst et al. 1999). The use of gnotobiotic animals associated with one or more species of bacteria has led to the recognition of Bifidobacteria and other LAB as potential therapeutic agents (Duffy et al. 1999). It is likely that many or most of the mechanisms of immunomodulation demonstrated for probiotic species will be 
shared with $\beta$-fructans and other NDO that encourage the growth and metabolism of LAB already resident in the GIT.

The research with animal models has revealed three lines of host defense. The first is the assemblages of bacteria resident in the different regions of the GIT. The second line of defense is the multilayered mucosal barrier that acts as a selective filter for absorption of water, nutrients, and electrolytes, but must exclude pathogens, hazardous chemicals, and other potential challenges to health. The third line of defense consists of the systemic mechanisms that must recognize and eliminate any potentially harmful organisms or chemicals that manage to transcend the mucosal barrier. The defense mechanisms are generally considered to include those that act against antigens that can be recognized and eliminated by the innate and acquired components of the immune system. This review also includes the mechanisms of defense associated with the xenobiotic metabolizing enzymes that are important for transforming and eliminating compounds that are not recognized by the immune system, yet pose a risk to health. The relationship among the GIT bacteria, host defense, and health is well recognized and the modulation by inulin, oligofructose, and other NDO has been the subject of numerous reviews. Therefore, the following sections will focus on the latter two lines of defense, the associated mechanisms, and the potential and realized responses to diets supplemented with inulin, oligofructose, and other NDO.

\section{Defense mechanisms of the gastrointestinal tract}

Before a pathogen or toxin present in the GIT can enter the host, it must first cross the multilayered mucosal defenses. The availability of genetically manipulated animals has assisted in understanding how the GIT bacteria modulate mucosal defenses. Exemplary is the protection provided by LAB to interleukin 10 knockout mice that are predisposed to inflammatory bowel disease (Madsen et al. 1999). Probiotic LAB have been considered as immunomodulators because they enhance mucosal defense functions and reduce bacterial translocation in animal models (Lee et al. 2000; Herias et al. 1999), with similar findings for humans (Hove et al. 1999). Since inulin, oligofructose and other NDO increase LAB densities, it is likely they provide health benefits that are similar to those obtained with LAB-based probiotics.

Bacterial regulation of various GIT immune functions is well established (Fuller \& Perdigon, 2000; Neish et al. 2000; MacDonald \& Pettersson, 2000; Lefrancois \& Goodman, 1989). The co-evolution of bacteria with host animals (Carman et al. 1993) has resulted in GIT immune responses that are able to differentiate between commensal and exotic species of bacteria (Berg \& Savage, 1975). The relationship is obvious from the changes in immune cell populations and proportions of immune-related cells of the GIT following microbial colonization of gnotobiotic animals, with the responses varying among the species that are introduced. (Falk et al. 1998; Imaoka et al. 1996; Helgeland et al. 1996). Gnotobiotic and newborn animals have functional immune systems, but the cell populations are smaller, are present in different proportions, are not fully activated. As a consequence, the responses to viruses and other pathogens differ from those of animals with diverse and established assemblages of bacteria (Cebra, 1999).

The interactions between the GIT bacteria and the mucosal defenses are more pronounced during infancy when the bacterial populations are undergoing successional changes and there is a greater risk of bacterial translocation leading to systemic disease (Duffy, 2000). Postnatal successional changes in the resident bacteria coincide with development of GIT structural and functional characteristics. The resident bacteria influence GIT synthesis of protein and DNA (Muramatsu, 1990), are critical for development of the defense functions (Kalliomäki et al. 2001; Kirjavainen \& Gibson, 1999; Cebra, 1999), and influence the risk of bacterial translocation (Berg, 1995).

The mucous secreted by epithelial cells is the first layer of mucosal defense and consists of a combination of immunoglobulin A (IgA), antimicrobial peptides, and a complex mixture of glycosylated proteins that are coded for by several genes. The various glycoproteins in mucous are capable of binding pathogens, preventing them from adhering to the epithelium (Mack \& Sherman, 1991), can inhibit replication of some viruses (Yolken et al. 1994), and may provide a nutrient source to $\mathrm{LAB}$ and other commensal bacteria. It is not surprising that disruption of mucous secretion is associated with inflammatory bowel disease (Shirazi et al. 2000). Mucous secretion is dependent on lumenal nutrients (Spaeth et al. 1994), but supplementing the diet with fiber increases secretion (Sharma \& Schumacher, 1995; Bengmark \& Jeppsson, 1995), with the magnitude of increase varying among sources of fiber (Vahouny et al. 1985).

The immunoglobulin A (IgA) secreted by B-lymphocytes (plasma cells) in the lamina propria of the mucosa is directed to specific antigens present in the lumen of the GIT, including antigens associated with the commensal bacteria (Macpherson et al. 2000). Fibers that are fermented by the LAB increase secretion of $\operatorname{IgA}$ into the GIT (Kudoh et al. 1999), and this may reduce development of allergic reactions to food antigens (Cross \& Gill, 2001; Kirjavainen \& Gibson, 1999).

The antimicrobial peptides secreted by the GIT are another important component of the innate immune system (Hancock \& Scott, 2000). At the present time, the relationship among the antimicrobial peptides, the GIT bacteria, and diet are poorly understood, and to our knowledge nothing is known about the influence of supplementing the diet with NDO. However, the increased activity of other innate defenses (e.g. macrophages and NK cells) in response to $\mathrm{LAB}$ (reviewed by McCracken \& Gaskins, 1999) and NDO (our own unpublished findings) suggest that constituitive expression of antimicrobial peptides may be modulated by changes in the GIT bacteria.

Another level of mucosal defense is provided by the epithelial cells, which are capable of antigen presentation, secretion of cytokines, and can recruit immune cells (e.g. macrophages). The high rates of epithelial cell proliferation and turnover, though costly, remove compromised cells and limit the movement of pathogens and noxious 
chemicals from the lumen to the host. Oligofructose stimulates higher rates of colonocyte proliferation than cellulose and other NDO (Howard et al. 1995), without increasing the total amount of mucosa. Similarly, soy polysaccharide increases proliferation of enterocytes and colonocytes and enhances mucosal structure and functions (Chinery et al. 1992). These findings partly explain why different sources of fiber provide varying resistance to health challenges.

The final layer of the GIT defense that protects against pathogens includes the B-lymphocytes, CD4 and CD8 T-lymphocytes in the organized lymphoid tissues in the wall of the GIT (e.g. Peyer's patches), and the immune associated cells scattered throughout the lamina propria and amongst the epithelial cells. Secretion of IgA by the B-cells provides lumenal protection, whereas the T-cells respond to bacterial translocation and other health threats (Lee et al. 2000; Gautreaux et al. 1994). The patterns of immune function modulation in the GIT vary among sources of fiber (Lim et al. 1997) and the regions and tissue layers of the GIT. Feeding dogs a diet with fermentable fiber increases the ratio of $\mathrm{CD}^{+}: \mathrm{CD}^{+}$cells in the lymphoid tissues, but increases the proportion of $\mathrm{CD}^{+}$in the lamina propria and intraepithelial cell populations (Field et al. 1999). The same diet resulted in lower numbers of circulating B-cells, but did not affect the activity of natural killer cells associated with the GIT. These findings are shared with other species (McCracken \& Gaskins, 1999) and suggest diets with fermentable fiber do not change the types and functions of immune cells, but instead alter the distribution, relative abundance, and specific responses.

The xenobiotic metabolizing enzymes expressed by the epithelial cells of the GIT provide a mechanism of protection against some environmental toxins. The enzymes of the epithelial cells mainly catalyze oxidative reactions and expression is responsive to changes in diet and the GIT bacteria (Ilett et al. 1990). The highest activities are measured in the jejunum. Activities of the epithelium are lower in the colon, where bacterial transformation dominates (Peters et al. 1991; Ilett et al. 1990), and the processes are mainly reductive (Rowland et al. 1986). Despite the importance of this defense mechanism, it has received little attention, and even less is known about the possible modulation of xenobiotic metabolizing enzymes by dietary supplements of inulin, oligofructose, and other NDO.

\section{Systemic host defense mechanisms}

Animals have evolved defense mechanisms to respond to pathogens or to noxious compounds that transcend the mucosal barrier and enter the host. The types and magnitude of responses by the systemic defenses to antigens differ somewhat from those of the GIT. However, the ability of probiotics to enhance systemic defenses, increase resistance to health challenges, and potentiate vaccine responses (Fuller \& Perdigon, 2000; McCracken \& Gaskins, 1999) demonstrates that there are interactions between the GIT bacteria and systemic immune functions. Systemic immune responses vary according to the source of fiber (Cavaglieri et al. 2000; Schiffrin, 1997). Feeding mice diets supplemented with inulin and oligofructose increased activities of natural killer cells and phagocytes (our unpublished data) and enhanced T-lymphocyte functions (Pierre et al. 1999) more so compared to mice fed diets with cellulose or lacking fiber. These results are consistent with the observation of heightened resistance to systemic infections with Listeria and Salmonella (Buddington et al. 2002), the lower incidence and growth of tumors after exposure to carcinogens (Reddy, 1999) and transplanted tumor cells (Taper et al. 1998), and are in agreement with enhanced innate and acquired immune functions provided by Lactobacillus and other LAB (Fuller \& Perdigon, 2000; Miake et al. 1985; Sato, 1984). Interestingly, circulating white blood cell counts were lower in mice fed the diets with inulin and oligofructose. Ratios for $\mathrm{CD}^{+}$relative to $\mathrm{CD}^{+} \mathrm{T}$-lymphocytes and $\mathrm{T}$ - relative to B-lymphocytes from the spleen and thymus did not differ between mice fed the diets with $\beta$-fructans and cellulose (our unpublished data). These findings are suggestive of a shift to a greater dependence on cell-mediated immunity, a Th1 state (Pratt et al. 1996; Taga \& Kishimoto, 1995; Thompson, 1994). Corroborating this contention, supplementing diets with NDO changes cytokine concentrations and profiles (Maassen et al. 2000; Lim et al. 1997), increases blastogenic activity of mesenteric lymph node lymphocytes, decreases the responses of T-lymphocytes isolated from Peyer's patches, and lowers IgE synthesis (Field et al. 1999).

Transformation of noxious chemicals by the liver and other tissues augments the activities of the GIT bacteria and mucosa. The combined activities of the xenobiotic metabolizing enzymes of the GIT, the resident GIT, and the liver and other tissues influence the route of excretion, with water soluble metabolites eliminated in the urine and lipid soluble metabolites recycled to the GIT by the bile. Hepatic transformation of mutagenic metabolites of carcinogens can be modulated by fiber (Helsby et al. 2000) and by the densities of LAB in the GIT (Nugon-Baudon et al. 1998), with the responses varying among the numerous xenobiotic metabolizing enzymes. These findings suggest diet may be an important determinant of the mechanisms of host defenses that are associated with the transformation, disposition, and accumulation of noxious chemicals.

\section{Signaling between the gastrointestinal tract bacteria and host defenses}

The ability of LAB and other GIT bacteria to influence defense functions can be indirect. This would include the host's responses to SCFA and other bacterial metabolites (Sakata et al. 1999). For example, mucin secretion by the rat colon is stimulated by an increase in lumenal concentrations of SCFA, but not by lactate or succinate (Shimotoyodome et al. 2000). Furthermore, butyrate, a SCFA of particular importance to the GIT, enhances defense functions of both the small and large intestine (Wachtershauser \& Stein, 2000) and stimulates mucosal growth by increasing the proliferation of enterocytes and colonocytes (Ichikawa \& Sakata, 1998). In addition to serving as an important source of energy, SCFA trigger the secretion of several GIT trophic hormones (Tappenden 
\& McBurney, 1998; Tappenden et al. 1997, 1996; Reilly et al. 1995). Supplementing diets with inulin, oligofructose and other NDO should increase production of SCFA, and particularly butyrate, and can be predicted to strengthen mucosal defenses and enhance responses to health challenges. In addition to metabolites, components of bacterial cells (e.g. lipopolysaccharides) are well known as potent modulators of immune functions.

The interactions between the bacteria and host defenses can be direct and involve attachment of GIT bacteria to receptors of host cells, thereby permitting 'cross-talk'. The best-known examples are those involving the interactions between pathogens and epithelial cells causing changes in functions of the cells and the GIT (Uzzau \& Fasano, 2000; Pothoulakis, 2000). Some species of GIT bacteria induce specific patterns of gene expression that alter the local environment (Bry et al. 1996). Adherence of Lactobacilli to receptors of epithelial cells can induce expression of genes coding for variants of intestinal mucins that inhibit the adherence of enteropathogenic $E$. coli to the epithelium (Mack et al. 1999). The secretion of regulatory cytokines that influence host defenses is modulated by bacteria, with host responses depending on the types and proportions of the secreted cytokines (Maassen, 2000; Pothoulakis, 2000; Chen et al. 1999). The cytokines secreted from the GIT provide a signaling mechanism to influence systemic defenses. In addition, lymphocytes of the GIT enter the systemic circulation after interacting with antigen and then differentiate and mature in the germinal vesicles of lymphoid follicles (Lim et al. 1997).

\section{Perspectives}

Although the LAB modulate immune functions, not all species of LAB elicit the same type and magnitude of responses (reviewed by Fuller \& Perdigon, 2000 and McCracken \& Gaskins, 1999). Similarly, not all sources of fiber, nor all NDO, provide the same benefits or increase resistance to health challenges (Alles et al. 1999). There is a need to identify specific NDO (alone or in combination) that provides the greatest resistance to health challenges. Inter-individual variation in the assemblages of GIT bacteria will influence the types and magnitude of responses to NDO. This will complicate attempts to identify a "universal' NDO supplement. Getting past the perception of prebiotics as 'conbiotics' will require additional research and a better understanding of the interactions among NDO, the GIT bacteria, and the multiple defense mechanisms of the host. Obviously, animal models will continue to play an important role.

Immunosuppressed patients are at greater risk of infections originating from the GIT. Yet, to our knowledge, the possible benefits such patients may gain from diets supplemented with NDO have yet to be investigated. There is also a need to better understand, if and how, NDO can be used to reduce accumulation of environmental contaminants and other noxious chemicals.

\section{References}

Alles MS, Hartemink R, Meyboom S, Harryvan JL, Van Laere KMJ, Nagengast FM \& Hautvast JGAJ (1999) Effect of transgalactooligosaccharides on the composition of the human intestinal microflora and on putative risk markers for colon cancer. American Journal of Clinical Nutrition 69, 980-991.

Bailey JS, Blankenship LC \& Cox NA (1991) Effect of fructooligosaccharide on Salmonella colonization of the chicken intestine. Poultry Science 70, 2433-2438.

Bengmark S (1998) Ecological control of the gastrointestinal tract. The role of probiotic flora. Gut 42, 2-7.

Bengmark S \& Jeppsson B (1995) Gastrointestinal surface protection and mucosa reconditioning. Journal of Parenteral and Enteral Nutrition 19, 410-415.

Berdanier CD (1994) Advanced Nutrition: Macronutrients, Modern Nutrition, Vol. 1, Boca Raton, FL: CRC Press.

Berg RD (1995) Inhibition of bacterial translocation from the gastrointestinal tract to the mesenteric lymph nodes in specific pathogen-free mice but not gnotobiotic mice by non-specific macrophage activation. Advances in Experimental Medicine and Biology 371A, 447-452.

Berg RD \& Savage DC (1975) Immune responses of specific pathogen-free and gnotobiotic mice to antigens of indigenous and nonindigenous microorganisms. Infection and Immunity 11, 320-329.

Bovee-Oudenhoven IMJ, Termont DSML, Heidt PJ \& Van der Meer R (1997) Increasing the intestinal resistance of rats to the invasive pathogen Salmonella enteritidis: additive effects of dietary lactulose and calcium. Gut 40, 497-505.

Bry L, Falk PG, Midtevedt T \& Gordon JI (1996) A model of host-microbial interactions in an open mammalian ecosystem. Science 273, 1380-1383.

Buddington KK, Donahoo JB \& Buddington RK (2002) Dietary oligofructose and inulin provide mice with protection against enteric and systemic pathogens and tumor inducers. Journal of Nutrition 132, 80-87.

Carman RJ, Van Tassel RL \& Wilkins TD (1993) The normal intestinal microflora: ecology, variability and stability. Veterinary and Human Toxicology 35, 11-14.

Catala I, Butel MJ, Bensaada M, Popot F, Tessedre AC, Rimbault A \& Szylit O (1999) Oligofructose contributes to the protective role of bifidobacteria in experimental necrotizing enterocolitis in quails. Journal of Medical Microbiology 48, 89-94.

Cavaglieri CR, Martins EF, Colleone VV, Rodrigues C, Vecchia MG \& Curi R (2000) Fiber-rich diets alter rat intestinal leukocytes metabolism. Journal of Nutritional Biochemistry 11, $555-561$.

Cebra JJ (1999) Influences of microbiota on intestinal immune system development. American Journal of Clinical Nutrition 69, $1046 \mathrm{~S}-1051 \mathrm{~S}$.

Chandra G, Oli M, Petschow BW \& Buddington RK (1996) Changes in pig intestinal structure and functions and resident microbiota induced by acute secretory diarrhea. In Advances in Swine in Biomedical Research, pp. 769-777, Chapter 67 [ME Tumbleson and LA Shook, editors]. New York, NY: Plenum Press.

Chen T, Isomaki P, Rimpilainen M \& Toivanen P (1999) Human cytokine responses induced by Gram-positive cell walls of normal intestinal microbiota. Clinical and Experimental Immunology 118, 261-267.

Chinery R, Goodland RA \& Wright NA (1992) Soy polysaccharide in an enteral diet: effects on rat intestinal cell proliferation, morphology, and metabolic function. Clinical Nutrition 11, $277-283$.

Cross ML \& Gill HS (2001) Can immunoregulatory lactic acid 
bacteria be used as dietary supplements to limit allergies? Allergy and Immunology 126, 112-119.

Cummings JH, Bingham SA, Heaton KW \& Eastwookd MA (1992) Fecal weight, colon cancer risk, and dietary intake of nonstarch polysaccharides (dietary fiber). Gastroenterology 103, $1783-1789$.

Cunningham-Rundles S \& Lin DH (1998) Nutrition and the immune system of the gut. Nutrition 14, 573-579.

Dai D \& Walker WA (1999) Protective nutrients and bacterial colonization in the immature human gut. Advances in Pediatrics 46, 353-382.

Deitch EA, Xu D, Qi L \& Berg R (1993) Elemental diet-induced immune suppression is caused by both bacterial and dietary factors. Journal of Parenteral and Enteral Nutrition 17, $332-336$.

Deng GY, Liu YW, He GZ \& Jiang ZM (1999) Effect of dietary fiber on intestinal barrier function of 5-FU stressed rats. Research in Experimental Medicine (Berlin) 199, 111-119.

Dewhirst FE, Chien C-C, Paster BJ, Ericson RL, Orcutt RP, Schauer DB \& Fox JG (1999) Phylogeny of the defined murine microbiota: Altered Schaedler Flora. Applied and Environmental Microbiology 65, 3287-3292.

Duffy LC (2000) Interactions mediating bacterial translocation in the immature intestine. Journal of Nutrition 130, 432S$436 \mathrm{~S}$.

Duffy LC, Leavens A, Griffiths E \& Dryja D (1999) Perspectives on bifidobacteria as biotherapeutic agents in gastrointestinal health. Digestive Diseases and Sciences 44, 1499-1505.

Erickson KL \& Hubbard NE (2000) Probiotic immunomodulation in health and disease. Journal of Nutrition 130, 403S-409S.

Falk PG, Hooper LV, Midtvedt T \& Gordon JI (1998) Creating and maintaining the gastrointestinal ecosystem: What we know and need to know from gnotobiology. Microbiology and Molecular Biology Reviews 62, 1157-1170.

Field CJ, McBurney MI, Massimino S, Hayek MG \& Sunvold GD (1999) The fermentable fiber content of the diet alters the function and composition of canine gut associated lymphoid tissue. Veterinary Immunology and Immunopathology 72, 325-341.

Frankel W, Zhang W, Singh A, Bain A, Satchithanandam S, Klurfeld D \& Rombeau J (1995) Fiber: effect on bacterial translocation and intestinal mucin content. World Journal of Surgery 19, 144-149.

Fukata T, Sasai K, Miyamoto T \& Baba E (1999) Inhibitory effects of competitive exclusion and fructooligosaccharide, singly and in combination, on Salmonella colonization of chicks. Journal of Food Protection 62, 229-233.

Fuller R \& Perdigon G (2000) Probiotics 3: Immunomodulation by the Gut Microflora and Probiotics, 275pp. Dordrecht, The Netherlands: Kluwer Academic Publishers.

Gaskins HR, Mackie RI, May T \& Garleb KA (1996) Dietary fructo-oligosaccharides modulate large intestinal inflammatory responses to Clostridium difficile in antibiotic-compromised mice. Microbial Ecology in Health and Disease 9, 157-166.

Gautreaux MD, Deitch EA \& Berg RD (1994) T lymphocytes in host defense against bacterial translocation from the gastrointestinal tract. Infection and Immunity 62, 2874-2884.

Gibson GT \& Roberfroid MB (1995) Dietary modulation of the human colonic microbiota: introducing the concept of prebiotics. Journal of Nutrition 125, 1401-1412.

Guandalini S, Pensabene L, Zikri MA, Dias JA, Casali LG, Hoekstra H, Kolacek S, Massar K, Micetic-Turk D, Papadopoulou A, de Sousa JS, Sandhu B, Szajewska H \& Weizman Z (2000) Lactobacillus GG administered in oral rehydration solution to children with acute diarrhea: A multicenter European trial. Journal of Pediatric Gastroenterology and Nutrition 30 , 54-60.

Hancock REW \& Scott MG (2000) The role of antimicrobial peptides in animal defenses. Proceedings of the National Academy of Sciences 97, 8856-8861.

Helgeland L, Vaage JT, Rolstad B, Midtvedt T \& Brandtzaeg P (1996) Microbial colonization influences composition and Tcell receptor $\mathrm{V}$ beta repertoire of intraepithelial lymphocytes in rat intestine. Immunology 89, 494-501.

Helsby NA, Zhu S, Pearson AE, Tingle MD \& Ferguson LR (2000) Antimutagenic effects of wheat bran diet through modification of xenobiotic metabolizing enzymes. Mutation Research 454, 77-88.

Herias MV, Hessle C, Telemo E, Midtvedt T, Hanson LA \& Wold AE (1999) Immunomodulatory effect of Lactobacillus plantarum colonizing the intestine of gnotobiotic rats. Clinical and Experimental Immunology 116, 283-290.

Honda K, Matsumoto T, Kuroki F, Tida M, Oka M \& Sawatani I (1999) Protective effect of lactosucrose on intracolonic indomethacin-induced small intestinal ulcers in rats. Scandinavian Journal of Gastroenterology 34, 264-269.

Hove H, Nørgaard H \& Mortensen PB (1999) Lactic acid bacteria and the human gastrointestinal tract. European Journal of Clinical Nutrition 53, 339-350.

Howard MD, Gordon DT, Pace LW, Garleb KA \& Kerley MS (1995) Effects of dietary supplementation with fructooligosaccharides on colonic microbiota populations and epithelial cell proliferation in neonatal pigs. Journal of Pediatric Gastroenterology and Nutrition 21, 297-303.

Ichikawa H \& Sakata T (1998) Stimulation of epithelial cell proliferation of isolated distal colon of rats by continuous colonic infusion of ammonia or short-chain fatty acids is nonadditive. Journal of Nutrition 128, 843-847.

Ikegami S, Umegaki K, Kawashima Y \& Ichikawa T (1994) Viscous indigestible polysaccharides reduce accumulation of pentachlorobenzene in rats. Journal of Nutrition 124, 754-760.

Ilett KF, Tee LBG, Reeves PT \& Minchin RF (1990) Metabolism of drugs and other xenobiotics in the gut lumen and wall. Pharmacology and Therapy 46, 67-93.

Imaoka A, Matsumoto S, Setoyama H, Okada Y \& Umesaki Y (1996) Proliferative recruitment of intestinal intraepithelial lymphocytes after microbial colonization of germ-free mice. European Journal of Immunology 26, 945-948.

Ishizuka S, Ito S, Kasai T \& Hara H (2000) Dietary sugar beet fiber ameliorates diarrhea as an acute gamma-radiation injury in rats. Radiation Research 154, 261-267.

Kalliomäki M, Kirjavainen P, Eerola E, Ker P, Salminen S \& Isolauri E (2001) Distinct patterns of neonatal gut microflora in infants in whom atopy was and was not developing. Journal of Allergy and Clinical Immunology 107, 129-134.

Kimura Y, Nagata Y, Bryant CW \& Buddington RK (2002) Nondigestible oligosaccharides do not increase accumulation of lipid soluble environmental contaminants by mice. Journal of Nutrition 132, 80-87.

Kirjavainen PV \& Gibson GR (1999) Healthy gut microflora and allergy: factors influencing development of the microbiota. Annals of Medicine 31, 288-292.

Kudoh K, Shimizu J, Ishiyama A, Wada M, Takita T, Kanke Y \& Innami S (1999) Secretion and excretion of immunoglobulin A to cecum and feces differ with type of indigestible saccharides. Journal of Nutritional Sciences Vitaminology 45, 173-181.

Lee DJ, Drongowski RA, Coran AG \& Harmon CM (2000) Evaluation of probiotic treatment in a neonatal animal model. Pediatric Surgery International 16, 237-242.

Lefrancois L \& Goodman T (1989) In vivo modulation of cytolytic activity and Thy- 1 expression in $\mathrm{TCR}^{-}{ }^{+}$intraepithelial lymphocytes. Science 243, 1716-1718.

Letellier A, Messier S, Lessard L \& Quessy S (2000) Assessment of various treatments to reduce carriage of Salmonella in swine. Canadian Journal Veterinary Research 64, 27-31. 
Lim BO, Yamada K, Nonaka M, Kuramoto Y, Hung P \& Sugano M (1997) Dietary fibers modulate indices of intestinal immune function in rats. Journal of Nutrition 127, 663-667.

Maassen C, Laman JD, Boersma WJA \& Claassen E (2000) Modulation of cytokine expression by lactobacilli and its possible therapeutic use. In Probiotics 3: Immunomodulation by the Gut Microflora and Probiotics, pp. 176-192. Dordrecht, The Netherlands: Kluwer Academic Publishers.

MacDonald TT \& Pettersson S (2000) Bacterial regulation of the intestinal immune responses. Inflammatory Bowel Diseases 6 , $116-122$.

Mack DR \& Sherman PM (1991) Mucin isolated from rabbit colon inhibits in vitro binding of Escherichia coli RDEC-1. Infection and Immunity 59, 1015-1023.

Mack DR, Michail S, Wei S, McDougall L \& Hollingsworth MA (1999) Probiotics inhibit enteropathogenic E. coli adherence in vitro by inducing intestinal mucin gene expression. American Journal of Physiology 276, G941-G950.

Macpherson AJ, Gatto D, Sainsbury E, Harriman GR, Hengartner H \& Zinkernagel RM (2000) A primitive T cell-independent mechanism of intestinal mucosal IgA responses to commensal bacteria. Science 288, 222-226.

Madsen KL, Malfair D, Gray D, Doyle JS, Jewell LD \& Fedorak RN (1999) Interleukin-10 gene-deficient mice develop a primary intestinal permeability defect in response to enteric microflora. Inflammatory Bowel Diseases 5, 262-270.

Malin M, Suomalainen H, Saxelin M \& Isolauri E (1996) Promotion of IgA immune response in patients with Crohn's disease by oral bacteriotherapy with Lactobacillus GG. Annals of Nutrition and Metabolism 40, 137-145.

Mao Y, Nobaek S, Kasravi B, Adawi D, Stenram U, Molin G \& Jeppsson B (1996) The effects of Lactobacillus strains and oat fiber on methotrexate-induced enterocolitis in rats. Gastroenterology 111, 334-344.

May T, Mackie RI \& Garleb KA (1995) Effect of dietary oligosaccharides on intestinal growth and tissue damage by Clostridium difficile. Microecology and Therapy 23, 158-170.

McCracken VJ \& Gaskins HR (1999) Probiotics and the immune system. In Probiotics: A Critical Review, pp. 85-111 [GW Tannock, editor]. Wymondham, UK: Horizon Scientific Press.

Miake S, Nomoto K, Yokokura T, Yoshikai Y, Mutai M \& Nomoto K (1985) Protective effect of Lactobacillus casei on Pseudomonas aeruginosa in mice. Infection and Immunity $\mathbf{4 8}$, $480-485$.

Morita K, Hirakawa H, Matsueda T, Iida T \& Tokiwa H (1993) Stimulating effect of dietary fiber on fecal excretion of polychlorinated dibenzofurans (PCDF) and polychlorinated dibenzo- $p$-dioxins (PCDD) in rats. Fukuoka Igaku Zasshi 84, 273-281.

Morita K, Hamamura K \& Iida T (1995) Binding of PCB by several types of dietary fiber in vivo and in vitro. Fukuoka Igaku Zasshi 86, 212-217.

Muramatsu T (1990) Gut microflora and tissue protein turnover in vivo in animals. International Journal of Biochemistry 22 , $793-800$.

Neish AS, Gewirtz AT, Zeng H, Young AN, Hobert ME, Karmali V, Rao AS \& Madara JL (2000) Prokaryotic regulation of epithelial responses by inhibition of $1 \kappa \mathrm{B} \alpha$-ubiquination. Science 289, 1560-1563.

Nugon-Baudon L, Rabot S, Flinois J-P, Lory S \& Beaune Ph (1998) Effects of the bacterial status of rats on the changes in some liver cytochrome P450 (EC 1·14.14.1) apoproteins consequent to a glucosinolate-rich diet. British Journal of Nutrition 80, $231-234$.

Oli MW, Petschow BW \& Buddington RK (1998) Evaluation of fructooligosaccharide supplementation of oral electrolyte solutions for treatment of diarrhea. Recovery of the intestinal bacteria. Digestive Diseases and Sciences 43, 138-147.
Peters WHM, Kock L, Nagengast FM \& Kremers PG (1991) Biotransformation enzymes in human intestine: critical low levels in the colon? Gut 32, 408-412.

Pierre F, Perrin P, Bassonga E, Bornet F, Meflah K \& Menanteau $\mathrm{J}$ (1999) T cell status influences colon tumor occurrence in min mice fed short chain fructo-oligosaccharides as a diet supplement. Carcinogenesis 20, 1953-1956.

Pool-Zobel BL, Neudecker C, Domizlaff I, Ji S, Schillinger U, Rumney C, Moretti M, Vilarini I, Scassellati-Sforzolini R \& Rowland I (1996) Lactobacillus- and Bifidobacterium-mediated antigenotoxicity in the colon of rats. Nutrtition and Cancer 26, $365-380$.

Pothoulakis C (2000) Effects of Clostridium difficile toxins on epithelial cell barrier. Annals of the New York Academy of Sciences 915, 347-356.

Pratt VC, Tappenden KA, McBurney MI \& Field CJ (1996) Short-chain fatty acid-supplemented total parenteral nutrition improves nonspecific immunity after intestinal resection in rats. Journal of Parenteral and Enteral Nutrition 20, 264-271.

Reddy BS (1999) Possible mechanisms by which pro- and prebiotics influence colon carcinogenesis and tumor growth. Journal of Nutrition 129, 1478S-1482S.

Reilly KJ, Frankel WL, Bain AM \& Rombeau JL (1995) Colonic short chain fatty acids mediate jejunal growth by increasing gastrin. Gut 37, 81-86.

Rembacken BJ, Snelling AM, Hawkey PM, Chalmers DM \& Axon ATR (1999) Non-pathogenic Escherichia coli versus mesalazine for the treatment of ulcerative colitis: a randomized trial. Lancet 354, 635-639.

Rowland IR, Mallett AK, Flynn J \& Hargreaves RJ (1986) The effect of various dietary fibers on tissue concentration and chemical form of mercury after methylmercury exposure in mice. Archives of Toxicology 59, 94-98.

Sakata T, Ichikawa H \& Inagaki A (1999) Influences of lactic acid, succinic acid and ammonia on epithelial cell proliferation and motility of the large bowel. Asia Pacific Journal of Clinical. Nutrition 8, S9-S13.

Sato K (1984) Enhancement of host resistance again Listeria infection by Lactobacillus casei: role of macrophages. Infection and Immunity 44, 445-451.

Schiffrin EJ, Brassart D, Servin AL, Rochat F \& Donnet-Hughes A (1997) Immune modulation of blood leukocytes in humans by lactic acid bacteria: criteria for strain selection. American Journal of Clinical Nutrition 66, 515S-520S.

Shanahan F (2000) Probiotics and inflammatory bowel disease: Is there a scientific rationale. Inflammatory Bowel Diseases 6 , $107-115$.

Sharma R \& Schumacher U (1995) Morphometric analysis of intestinal mucins under different dietary conditions and gut flora in rats. Digestive Diseases and Sciences 40, 25322539.

Shimotoyodome A, Meguro S, Hase T, Tokimitsu I \& Sakata T (2000) Short chain fatty acids but not lactate or succinate stimulate mucus release in the rat colon. Comparative Biochemistry and Physiology 125A, 525-531.

Shirazi T, Longman RJ, Corfield AP \& Probert CSJ (2000) Mucins and inflammatory bowel disease. Postgraduate Medical Journal 76, 473-478.

Simpson JW (1998) Diet and large intestinal disease in dogs and cats. Journal of Nutrition 128, 2717S-2722S.

Spaeth G, Gottwald T, Specian RD, Mainous MR, Berg RD \& Deitch EA (1994) Secretory immunoglobulin A, intestinal mucin, and mucosal permeability in nutritionally induced bacterial translocation in rats. Annals of Surgery 220, 798-808.

Spaeth G, Berg RD, Specian RD \& Deitch EA (1990) Food without fiber promotes bacterial translocation from the gut. Surgery 108, 240-246. 
Szilagyi A (1997) Altered colonic environment, a possible predisposition to colorectal cancer and colonic inflammatory bowel disease: Rationale of dietary manipulation with emphasis on disaccharides. Canadian Journal of Gastroenterology 12, $133-146$.

Taga T \& Kishimoto T (1995) Signaling mechanisms through cytokine receptors that share signal transducing receptors components. Current Opinions in Immunology 7, 17-23.

Taper HS, Lemort C \& Roberfroid MB (1998) Inhibition effect of dietary inulin and oligofructose on the growth of transplantable mouse tumor. Anticancer Research 18, 4123-4126.

Tappenden KA \& McBurney MI (1998) Systemic short-chain fatty acids rapidly alter gastrointestinal structure, function, and expression of early response genes. Digestive Diseases and Sciences 43, 1526-1536.

Tappenden KA, Thomson ABR, Wild G, Tappenden E \& McBurney MI (1996) Short-chain fatty acids increase proglucagon and ornithine decarboxylase messenger RNAs after intestinal resection in rats. Journal of Parenteral and Enteral Nutrition 20, 357-362.

Tappenden KA, Thomson ABR, Wild G, Tappenden E \& McBurney MI (1997) Short-chain fatty acid-supplemented total parenteral nutrition enhances functional adaptation to intestinal resection in rats. Gastroenterology $\mathbf{1 1 2}$, $792-802$.
Thompson A (1994) The Cytokine Handbook. San Diego: Academic Press.

Umesaki Y \& Setoyama H (2000) Structure of the intestinal flora responsible for development of the gut immune system in a rodent model. Microbes and Infection 2, 1343-1351.

Uzzau S \& Fasano A (2000) Cross-talk between enteric pathogens and the intestine. Cell and Microbiology 2, 83-89.

Vahouny GV, Le T, Ifrim I, Satchithanandam S \& Cassidy MM (1985) Stimulation of intestinal cytokinetics and mucin turnover in rats fed wheat bran or cellulose. American Journal of Clinical Nutrition 41, 895-900.

Vanderhoof JA, Whitney DB, Antonson DL, Hanner TL, Lupo JV \& Young RJ (1999) Lactobacillus GG in the prevention of antibiotic-associated diarrhea in children. Journal of Pediatrics 135, 564-568.

Wachtershauser A \& Stein J (2000) Rationale for the luminal provision of butyrate in intestinal diseases. European Journal of Nutrition 39, 164-171.

Yolken RH, Ojeh C, Khatri IA, Khatri A, Sajjan U \& Forstner JF (1994) Intestinal mucins inhibit rotavirus replication in an oligosaccharide-dependent manner. Journal of Infectious Diseases 169, 1002-1006.

Zachar Z \& Savage DC (1979) Microbial interference and colonization of the murine gastrointestinal tract by Listeria monocytogenes. Infection and Immunity 23, 168-174. 